\title{
Perceptions of Healthcare Undergraduate Students about a Hospital Clown Training
}

\author{
Mauro Fantini Nogueira-Martins ${ }^{1}$, Daniele Lima-Costa ${ }^{1}$, Luiz Antonio Nogueira-Martins ${ }^{2}$, \\ Maria Cezira Fantini Nogueira-Martins ${ }^{3}$ \\ ${ }^{1}$ Centro Universitário São Camilo, São Paulo, Brazil \\ ${ }^{2}$ Universidade Federal de São Paulo (UNIFESP), São Paulo, Brazil \\ ${ }^{3}$ Instituto de Saúde da Secretaria de Estado da Saúde de São Paulo, São Paulo, Brazil \\ Email: maurofantini@gmail.com
}

Received 14 March 2014; revised 14 April 2014; accepted 21 April 2014

Copyright (C) 2014 by authors and Scientific Research Publishing Inc.

This work is licensed under the Creative Commons Attribution International License (CC BY). http://creativecommons.org/licenses/by/4.0/

(c) (i) Open Access

\begin{abstract}
Hospital clowns work worldwide as a health humanization resort, providing interplay with patients, family and staff. This type of activity varies greatly in terms of professionalism, accountability and artistic methods. Recently, some healthcare universities have introduced the clown language to undergraduates, aiming to train non-technical skills, often underrated in traditional healthcare teaching. Two 64-hour weekly hospital clown trainings were performed in a healthcare university in São Paulo, Brazil, in 2011 and 2012, with students from different undergraduate courses. The objective of this study was to assess the students' perceptions about this training. Subjects were asked to answer an open-ended question about their experience during the training. Answers were analyzed following the thematic analysis principles. Five theme categories were found: 1) expectations about the training; 2) perceptions of developed skills; 3 ) difficulties, doubts and unquietness; 4) influences on social and academic settings; 5) clown concepts after the training. Students highlighted improvement of listening, sustaining eye contact and dealing with failure as important apprehended concepts. The training process was considered deep and serious, and generated questioning and doubts in the subjects. Students reported influences on their daily activities, namely relationship improvement with family, friends and patients and enhanced of oral presentations. The clown training exhibited a potential for professional attitude construction and reflected on the students' lives, regarding development of interpersonal competencies.
\end{abstract}

\section{Keywords}

Hospital Clowns, Students, Health Occupation, Clown Training, Humanities/Education 


\section{Introduction}

For almost three decades clowns have been acting in hospitals alongside patients, family members and health professionals (Barkmann et al., 2013; Oppenheim et al., 1997) and are known by many names, such as hospital clowns, medical clowns or clown doctors (Warren \& Spitzer, 2011). Most published researches focus on the clown's work with children although today other types of unusual public and contexts are being approached by this red nose character, like psychiatric hospitals, refugee camps and business companies (Peacock, 2009).

The benefits of clowning in the health attendance setting have been previously studied. It has been demonstrated that the interaction with clowns can decrease preoperatory anxiety in children (Fernandes \& Arriaga, 2010; Vagnoli et al., 2005) and positively modify the patient's mood as perceived by behavior, facial expression and vocalization analysis (Kingsnorth et al., 2011). Bertini and colleagues have described that hospitalized children who had interacted with clowns presented a statistically significant decrease in diastolic blood pressure, respiratory frequency and body temperature, when compared to children who had not experienced the clown interplay (Bertini et al., 2011).

In Brazil, this kind of activity began with the Doutores da Alegria (Doctors of Joy), a group created in 1991 inspired by the New York-based Big Apple Circus Clown Care Unit. Since then, many Brazilian clown groups have been structured and worked in hospitals. Recently, both in Brazil (Françani et al., 1998; Lanzieri et al., 2011; Lima et al., 2009; Sorrir é Viver Medical University Clown Program Homepage, 2014), as in other countries (Siegel-Itzkovich, 2002; Washington University School of Medicine First Year Curriculum-Selective Courses-Medicine of Laughter, 2014), universities that offer healthcare courses have launched initiatives that aim to introduce the clown language to undergraduate students, who will be future physicians, nurses, physical therapists, among other professions. Firstly these programs offer clown training to the students, who, only after that, visit the hospital as clowns.

Koller and Gryski highlight the importance of training, since hospital clowns must learn how to subtly approach different people, such as babies, children, parents and hospital employees, with sensitivity and respect to the individual boundaries of each one (Koller \& Gryski, 2008). However, the characteristics and repercussions of clown training programs in university settings are scarce.

The objective of the present study was to assess the perceptions of healthcare undergraduate students that have attended a clown training in a university in the city of São Paulo, Brazil.

\section{Methods}

\subsection{Research Subjects}

In 2011, Centro Universitário São Camilo, a traditional private university in São Paulo, initiated a program called Narizes de Plantão (Noses on Duty) directed at training healthcare students in the clown language in order to constitute a group of hospital clowns. The program was proposed under logistic and artistic coordination by this study's first author, MFN-M, who is a professor at the institution and a professional clown. The present study was performed with two different groups of students, (A and B), who completed the artistic training at distinct semesters.

Group A: in June 2011, the program was officially divulged in the university community and 83 students voluntarily enrolled as candidates. After individual interviews, 40 students were selected to enter the program, based on interest and availability for the program's activities. Of the starting 40 students, 29 completed the full training, 9 voluntarily abandoned the program and 2 were excluded because of exceeding the absence limit. Of the 29 who completed the training, 20 agreed to answer the present work's instrument in November 2011. All of them were healthcare undergraduates who were attending the following courses: Medicine (11), Biomedicine (5), Occupational Therapy (3) and Nursing (1). The mean age of the sample was $21.5 \pm 1.4$ years and $85 \%$ were women. In regard to course year, distribution was as follows: 1 first-year, 9 second-year, 2 third-year, 7 fourthyear and 1 fifth-year students.

Group B: in June 2012, 63 students voluntarily enrolled as candidates do participate in the program. The same process of individual interviews was performed and 30 students were selected to enter the program. This time all 30 completed the training (no participant decided to quit or was excluded) and 28 of which agreed to answer the present work's instrument in November 2012. All of them were healthcare undergraduates who were attending the following courses: Medicine (6), Biomedicine (6), Nutrition (5), Physical Therapy (4), Occupational Thera- 
py (3), Nursing (3), and Psychology (1). The mean age of the sample was $22.1 \pm 1.5$ years and $90 \%$ were women. In regard to course year, distribution was as follows: 2 first-year, 3 second-year, 11 third-year, 11 fourth-year and 1 fifth-year students.

Subjects were asked to write an answer to the following open-ended question: "How was for you to take part in the clown training? Write as much as you want, do not worry with the text length". The answers were written in a free and anonymous fashion, allowing students to truthfully express their opinions and feelings.

The research has been approved by the institutional ethics committee and subjects agreed to enroll in the study upon signing an informed consent term.

\subsection{Clown Training}

The Narizes de Plantão (Noses on Duty) program is one of the university's humanization actions and is independent of the regular curriculum offered by the institution. Thus, taking part in the encounters or in the present research was not linked to any sort of academic evaluation that could influence approval in regular college disciplines.

The clown training was performed between August and October 2011, for group A, and between August and October 2012, for group B. It was structured by 16 weekly encounters with the whole groups. Each encounter was 4-hours long, adding up to a total of 64 hours. The encounters took place in a secluded wide room inside the university, at night (outside class hours) and were coordinated by three professional clowns with experience in hospital acting. Student frequency was strictly monitored and the ones with more than two absences were excluded from the program.

The training process aimed to provide the students with interpersonal connection tools, based on modern clown performance techniques. The main goal of a clown is to connect with the audience (or the patient) and this connection can be established through many paths that originate from the red nose mask, such as surprise, empathy, failure, competition, music, dance and many others. Thus, although many clowns are funny, humor does not comprise the only way by which a clown connects with people. In order to develop these various tools, the student must first get in touch with his/her own self, to unveil what are his/her unique talents, inadequacies, dreams and failures. Only then his/her clown can manifest as a potent and transforming character. This modern approach to clowning can be summarized by a teaching from Richard Pochinko, a famous Canadian clown, who states: "If we ever faced all directions of ourselves at once we could only laugh at the beauty of our own ridiculousness.” (Coburn \& Morrison, 2013: p. 27).

The encounters were based on practical theatre exercises that trained concepts of spontaneity, theatre improvisation, readiness, fragility and authenticity, inspired by the schools of Keith Johnstone (Johnstone, 2007), Richard Pochinko (Coburn \& Morrison, 2013) and Del Close (Halpern et al., 1994). Body actions and physical games within the clown language were also trained following the teachings of Jacques Lecoq (Lecoq et al., 2002). Since the work in hospitals takes place with clown duos (Linge, 2010) or triplets, which is called "clown marriage” (Warren \& Chodzinski, 2005) most exercises were collective, which aims to stimulate partnership, intimacy and interpersonal relationship. It is important that these abilities are trained first only among the students in a "safe environment", so they can be efficiently applied later during the hospital visits, with a real and live "audience". Students were also encouraged to create exclusive clown costumes and subtle makeup based on their own singular personalities and physical features.

\subsection{Data Analysis}

Data from the written open-ended question was analyzed following the thematic analysis principles (NogueiraMartins \& Bógus, 2004; Pope et al., 2000). The analyst triangulation technique was applied (Patton \& Patton, 2002) as follows: the material was thoroughly and repeatedly read by two authors (LANM and MCFNM) individually; each of these two last authors then created his own coding frames which aimed to identify emerging themes; after several meetings for coding comparisons and solving of disagreements, the final categories were defined and literal citations were chosen as representative fragments of each category.

\section{Results}

By using the thematic analysis approach on the answers to the open-ended questions, five broad categories were 
defined: expectations about the training; perceptions about developed skills; difficulties, doubts and unquietness; influences on social and academic settings; clown concepts after the training.

Literal citations are followed by the number assigned to the research subject responsible for the citation, and by the group to which the subject belonged (group A or B).

\subsection{Expectations about the Training}

Within this category, a clear difference between groups A and B was detected. Group A, which was the first to complete the training, had expectations very much related to the figure of the circus clown, a colorful, loud and outgoing character. Thus, for this group, some of the student's expectations about the training were not fulfilled.

They reported to have the previous belief that, when acting as clowns, they were supposed to be funny and smile frequently:

"I thought we would learn how to tell jokes, to be funny and to be always laughing happily, no matter what."

"I had a conception of the circus clown, so I thought I would draw the children's attention like these clowns do, talking loudly, having to be funny and in a good mood all the time." (15A)

"I thought we would learn tricks, gags and jokes to use at the hospital." (18A)

Still in group A, there were answers describing the surprise about the hospital clown activity being mainly improvised:

"I thought the games would be kind of rehearsed, that we would have something previously prepared before we came into the hospital, but now I see this is not necessary." (14A)

In contrast to the first group, subjects from group B had expectations which were closer to what would be approached during the training, mainly regarding the dynamic and fun aspects of it. This shift in expectations possibly arose because of previous information obtained with students from group A and/or because of program's growing fame within the University environment. There were, nevertheless, surprises as to the depth and accountability of the training process.

"Because of what people from the first group told me, I thought, at first, that the encounters would be useful for us to be less shy and to lose some of the shame we have when we are in embarrassing situations. But no, behind each exercise there was always a valuable lesson." (1B)

"Everything I thought was important in the beginning, I no longer see as necessary. The things I initially found irrelevant have taken another dimension. I never would have expected the great importance there is in body consciousness or looking your partner and the audience in the eye." (3B)

"I really wanted to participate in the training, because I knew it would be very interesting. The encounters started in a subtle, light fashion, as if they were only a place where we could play. But after a while they demanded more effort and dedication." (10B)

\subsection{Perceptions about Developed Skills}

The students reported that stimulation of self consciousness and the contact with their own fears and virtues were valid areas of learning:

"I learned how to deal with myself, with the stuff I have difficulties with and knowing what I am good at. I learned to deal with my mistakes and accept the mistakes from others." (20A)

Some considered to have learned how to deal with shyness and reported an improvement in personal interactions:

"I really learned to look the audience in the eye and not to be so nervous when many people were looking at me." (15B)

"I learned how to look at the other person and understand him, perceiving him by a simple look in the eye (whether he is another clown or a regular person I am interacting with)." (10A)

Some students highlight the importance of listening and of dealing with failure: 
"It was something that exceeded by expectations; the encounters made me look at things in which I had no interest at first; things like talking with people eye to eye, giving value to little things, admitting when I am good at something and also when I am terrible.” (6A)

"I learned to perceive the other person in a way I was not used to, noticing the person's physicality, body features, facial expressions and his/her 'energy', like when someone does not share his/her opinion or feelings using words, but instead uses facial expressions. Even then I can understand IF and HOW should I approach him/her.” (11B)

"I guess these concepts of observing the other person and dealing with failure are like riding a bike: I will never forget and I get better with practice..." (13B)

\subsection{Difficulties, Doubts and Unquietness}

Many difficulties during the training period were mentioned.

"I went through every experience: fear, anxiety, anguish, personal disappointment." (12B)

"When we talk about other people, it is all too easy: we can give every detail, point out every flaw, every quality, the manners, the way he/she walks or speaks, I mean, everything is easy. But when it comes to ourselves, things get complicated: we don't actually know how we walk, we can't point out our flaws (it is terribly hard) and, believe it or not, pointing out our own qualities is not so easy as well." (21B)

Some doubts that emerged from the training were related to relevance of the training process in respect to the academic activities:

"At the beginning, I asked myself: what am I doing here? I study Medicine and I want to be a clown? I didn't see a link between the two things at that time". (12A)

"When we had exams, some colleagues advised me to go study instead of attending the clown encounters. Sometimes I didn't know what would be best.” (18B)

Other students questioned their potential as acting clowns:

"I wonder if I will have good and quick reactions to the public." (6B)

"During the encounters, with our clown partners, it is easier. But I don't know if I will be able to share my ridiculous side with the world. Will the others respect me?” (13A)

Thoughts about the students' own behavior and attitudes were reported:

"The training made me think about occasions when I am somewhere only physically, but not with my full attention; about the fear of looking others in the eye, about how I have let myself enter an automatic lifestyle, in which I have only duties to carry out." (1A)

"At first, the encounters caused me a lot of doubts: who am I really? What do I or don't I like? What are my defects and qualities? Where will this training take me?” (14B)

Some students presented doubts about the program's final goal, the hospital visits, as a volunteer activity:

"I frequently had hesitations as to how much selfish I was being, because this is supposed to be a social program. And why do you enter in a social program: to satisfy your ego? For kindness? Both?” (5B)

"I have always wanted to participate in a social project and I kept questioning myself if this was the right one." (4A)

\subsection{Influences on Social and Academic Settings}

Students reported that the training had repercussions on their daily lives and affected their interpersonal dialogue.

There were reports of a better listening of family members, which was generally associated with improvements in the relationship:

“... I noted that now I feel and listen to my mother as if it were the first time during her repetitious stories and five/six all-too-similar already-answered questions within minutes. With that, I have perfected my dialogue with her and I can better understand my mother's memory loss." (16A) 
"At home, I guess the most important influence was to listen to what the other person is proposing, understand it, accept it and make the proposal work, as when my parents want to spend some time with me and invite me to do something, just for the company.” (2B)

To be more self-conscious has contributed to improve relationship with others, in the opinion of some students:

"Knowing my qualities and defects helps a lot when dealing with my friends." (11A)

"I learned to be more patient. If I don't like something that is said, I stop, breathe and keep on listening, as opposing to what I used to be, when I 'snapped' easily.” (17B)

Some students wrote that they applied the very trained exercises on family and friends:

"Actually, all the clowning we trained I use at home, because I have a six-year old sister and I end up playing a lot with her, making up songs, asking her to the same thing in a lot of different ways, or sometimes she decides to boss me around and I let it happen.” (5A)

"(...) one activity we did in one encounter influenced a lot my routine here at home. It influenced so much that I taught everyone who lives here. In one encounter we learned a very cool breathing method, making sounds as we exhale, giving us a sensation of peace and wellbeing. Every night before everybody sleeps here at home we do this 'method' and they say they sleep better and faster." (7B)

Enhanced perception in the academic scenario was cited by the students:

"I listen to the patients at the hospital during anamnesis as if it were the first time. Also, when entering an infirmary, I greet the patients around the one that is to be examined, even if just with a sympathetic look." (16A)

"I deal with people all the time, from the sickest ones to the silly competition that college offers us. The most important influence to me was to accept what the other person is proposing. I can't always be in charge and command things, nor will I always be right.” (8B)

According to some subjects, keeping eye contact with the audience was an important learning and was linked to better oral presentations:

"During seminar presentations I feel I look more steadily to the public, like we did in the exercises where we had to show up from behind the curtains and stare at the audience. This brought me more confidence and I believe I earn some extra points from the teachers regarding individual performance in presentations.” (16B)

The influence of dealing with failure during the university duties was highlighted:

"Accepting failure. This positively influences me because I learned to be more tolerant with myself and began to understand that everyone has flaws, starting by me." (25B)

"I used to be a little afraid of pushing the limits in the classroom in respect to asking too many questions and seeming ridiculous in front of my colleagues. Now I don't fear that anymore and I ask as many questions as needed to understand the subject." (11A)

\subsection{Clown Concepts after the Training}

Many definitions about being a clown were reported by the students:

"A clown is someone who is always ready and aware of everything, because he can 'enter the scene' at any time, and it can become a game." (3A)

"We have to let our judgment aside, our preconceived thoughts, we have to let our minds free and open to the stimuli that emerge. You don't become a clown from one day to another and wearing a red nose is not enough.” (28B)

"To use the world's smallest mask is a huge responsibility, I admit I didn't know it was such a responsibility...” (27B)

"The red nose makes you see a creative and glowing red shadow in front of you, making you look at ordinary objects, but seeing them as it was the first time, giving it new meanings and functions... I believe it 
changes people's ideas, not letting them give up easily. If you are at work, or writing a college essay... something gone wrong? Wait, we can do this in another way, with different structures, different outcomes..." (7A)

"I realized that, for us to go to the hospital, we need to be prepared to be unprepared." (24B)

\section{Discussion}

We have found that students were touched by the contact with the clown universe not because it is a funny, joking character, but mainly by the principles encompassing it. These principles generate the framework for the clown to establish creative, non-invasive and spontaneous relationships with others (the clown partner, patients, family, hospital staff). Participants highlighted the learning of connection tools, such as listening ability, keeping eye contact and dealing with failure.

The listening ability, a quality whose absence in students and healthcare professionals is severely criticized (Shooter, 2002), was perceived as outstanding for the clown activity, as observed in some answers. This is consistent with the fact that, in the hospital, a clown must heighten his listening abilities and "listen with all antennas up" (Warren \& Chodzinski, 2005) in order to fully understand the verbal and nonverbal messages sent by people around him, for one apparently superfluous piece of information may prove useful in creating a memorable scene or game.

Also, keeping eye contact was considered by the students as a relevant ability. Eye contact is solidly linked to the multisensory listening ability (which is more than just hearing) and, because of that, it has been studied as an important component of nonverbal communication in doctor-patient relationship (Gorawara-Bhat \& Cook, 2011). Thus, through sustained eye contact, students may enhance perception of incoming information, as well as upgrade message delivery, since an improvement in oral presentations has been reported.

Dealing with failure was likewise a recurrent theme in the students' perceptions about the encounters. The work of the hospital clown requires the artist to know his mistakes and to understand that his failure may just be what satisfies the public, that in return empathizes with him. In failing, the clown, weak and fool, puts himself in an inferior situation when compared to the patient, strong and smart. This creates a "reversed relation", which might be the initial sparkle to what Linge (Linge, 2012) calls "a magical relationship". For the artist who intends to be an improviser-clown, there are no recipes for mistakes and his clown's failures will have to be based on inadequacies belonging to the very actor. Being overweight, being extremely thin or not knowing geography are possible "failure areas" that a clown and the real life actor likely share. Therefore, the discovery and acceptance of one's shortcomings is a journey of self consciousness necessary to the good use of the red nose. Thus, the relationship with the audience (in the case of the hospital, the patients, family and staff) is established when the actor meets his unique "clown identity” (Masetti, 2003).

The difficulties experienced by the students, along with their doubts and unquietness, suggest a reflection about the care with which the coordinators of this type of programs must have with the participants. The guiding attention should be dispended not only to the whole group but also to each particular individual, so everyone can feel both safe and challenged enough in order to grow and to deal with fears and doubts. Generating a free, creative and non-judgemental training environment is pivotal, because the interactions between clowns and patients at the hospital usually reflect the ones between student, group and coordinators.

The students' perceptions pertained important concepts of the clown activity that can be transferred to dayto-day activities. Markedly, students reported that some clown features were already influencing academic duties and social interactions.

Some clown teachers say that the clown has child's eyes, that it has "innocence after experience" (Coburn \& Morrison, 2013: p. 181) because, although he is an adult, he sees everything as if it were the first time, which provides him with a powerful and curious point of view. This first-time look was reported as a positive developed ability by the students in different settings, such as interaction with family or relationship with patients.

The definitions given by the students at the end of the training highlight important aspects such as spontaneity, creativity, responsibility and sensitivity.

\subsection{Study Limitations}

Data were collected from a single health school. At the first training day, group A was composed of 40 students, but 11 of them left (abandoned or were excluded from) the training. Group B started with 30 participants and 
ended with the same number, since nobody left. Of the 59 remaining students (groups A + B), 48 agreed to participate in this research and answer the question, which comprises a representative sample of the whole group (81.3\%). Nevertheless, the obtained responses may not reflect the opinion of students who attended the full training but did not enroll in this research and, most importantly, may not mirror the impressions of the ones who evaded the course in the middle of the process.

\subsection{Possible Educational Implications}

The current paradigm of healthcare education demands an ensemble of technical and interpersonal competencies, which are developed in many scenarios, comprehending formal, parallel and hidden curricula (Nogueira-Martins et al., 2006). Regarding interpersonal competencies, there are many approaches being executed in healthcare universities in order to teach empathy, teamwork and interpersonal abilities , and some of them are based on arts and humanities, such as music (Janaudis et al., 2013), theatre (Hammer et al., 2011), movies (Blasco, 2011) and literature (Evans, 2003). The clowning experience is inserted in this context.

About the present study, it is plausible to assume that if the improvement in listening to others was transposed to the healthcare scenario, it could enhance the dialogue between healthcare students and patients or family. Moreover, sustaining eye contact was associated by the students with better oral presentations. Because presenting seminars or case reports has been identified as a source of stress in academic activity (Preuss et al., 2010), it is plausible to hypothesize that the clown training may have direct and indirect effects of reducing universityassociated stress.

Based on the obtained data, it is not possible to predict the influences of this educational intervention on the students' future professional attitudes. It would be interesting to follow these subjects up to their first years as professionals to confirm whether the clowning program's repercussions are permanent, as it has been proposed for the evaluation of long-term effects of other initiatives joining arts and medicine (Charon, 2010). Accordingly, a recent article (Leef \& Hallas, 2013) has studied professional nurses who had taken part in a clown training during college. The authors conclude that the nurses kept some abilities and attitudes developed during the training, even though it had occurred 18 months prior to the research.

\section{Conclusion}

The hospital clown training performed with undergraduate healthcare students presented a tendency to contribute to the development of non-technical skills, since it provokes changes in interpersonal competencies, provided that a comfortable framework is offered for the participants to establish creative, non-invasive and spontaneous relationships with others. It should be highlighted that the training process is to be coordinated with complete awareness, in order to guarantee the students' evolution and avoid that the artistic workshops are merely fun but aimless. The guiding attention should be dispended not only to the whole group but also to each particular individual, so everyone can feel both safe and challenged enough in order to grow and to deal with fears and doubts.

We believe that a clown training has an attitude-building potential for the healthcare student, provided that it is performed in a deep, well-fundamented, strict and continuous fashion. Since the clown training was highly fruitful, at least in this research, and inseparable from the unique particularities of each student, similar strategies should be stimulated in other teaching institutions, in a facultative manner, rather than mandatory, allowing the student to build his own artistic, professional and personal path.

\section{Acknowledgements}

We sincerely thank Claudio Thebas and Julieta Zarza, professional clowns who have helped coordinating the artistic encounters of Narizes de Plantão with outstanding talent and commitment. We also strongly thank Dr. Margareth Pedroso Zabeu, Dr. Eloi Francisco Rosa and Cristiane Yonezaki, whose help was essential for both the structuring of the clown program and for the execution of the present research.

\section{References}

Barkmann, C., Siem, A.-K., Wessolowski, N., \& Schulte-Markwort, M. (2013). Clowning as a Supportive Measure in Paediatrics-A Survey of Clowns, Parents and Nursing Staff. BMC Pediatrics, 13, 166. 
http://dx.doi.org/10.1186/1471-2431-13-166

Bertini, M., Isola, E., Paolone, G., \& Curcio, G. (2011). Clowns Benefit Children Hospitalized for Respiratory Pathologies. Evidence-Based Complementary and Alternative Medicine, 2011, 1-9. http://dx.doi.org/10.1093/ecam/neq064

Blasco, P. G. (2011). Educating through Movies: How Hollywood Fosters Reflection. Creative Education, 2, 174-180. http://dx.doi.org/10.4236/ce.2011.23024

Charon, R. (2010). Commentary: Calculating the Contributions of Humanities to Medical Practice-Motives, Methods, and Metrics. Academic Medicine: Journal of the Association of American Medical Colleges, 85, 935-937. http://dx.doi.org/10.1097/ACM.0b013e3181dc1ead

Coburn, V., \& Morrison, S. (2013). Clown through Mask the Pioneering Work of Richard Pochinko as Practised by Sue Morrison. Bristol: Intellect.

Evans, M. (2003). Roles for Literature in Medical Education. Advances in Psychiatric Treatment, 9, 380-385. http://dx.doi.org/10.1192/apt.9.5.380

Fernandes, S. C., \& Arriaga, P. (2010). The Effects of Clown Intervention on Worries and Emotional Responses in Children Undergoing Surgery. Journal of Health Psychology, 15, 405-415. http://dx.doi.org/10.1177/1359105309350231

Françani, G. M., Zilioli, D., Silva, P. R. F., Sant’ana, R. P. de M., \& Lima, R. A. G. de (1998). Prescrição do dia: Infusão de alegria. Utilizando a arte como instrumento na assistência à criança hospitalizada. Revista Latino-Americana de Enfermagem, 6, 27-33. http://dx.doi.org/10.1590/S0104-11691998000500004

Gorawara-Bhat, R., \& Cook, M. A. (2011). Eye Contact in Patient-Centered Communication. Patient Education and Counseling, 82, 442-447. http://dx.doi.org/10.1016/j.pec.2010.12.002

Halpern, C., Close, D., \& Johnson, K. (1994). Truth in Comedy: The Manual for Improvisation. Meriwether Pub.

Hammer, R. R., Rian, J. D., Gregory, J. K., Bostwick, J. M., Barrett Birk, C., Chalfant, L., \& Hall-Flavin, D. K. (2011). Telling the Patient's Story: Using Theatre Training to Improve Case Presentation Skills. Medical Humanities, 37, $18-22$. http://dx.doi.org/10.1136/jmh.2010.006429

Janaudis, M. A., Fleming, M., \& Blasco, P. G. (2013). The Sound of Music: Transforming Medical Students into Reflective Practitioners. Creative Education, 4, 49-52. http://dx.doi.org/10.4236/ce.2013.46A009

Johnstone, K. (2007). Impro: Improvisation and the Theatre. A\&C Black.

Kingsnorth, S., Blain, S., \& McKeever, P. (2011). Physiological and Emotional Responses of Disabled Children to Therapeutic Clowns: A Pilot Study. Evidence-Based Complementary and Alternative Medicine: eCAM, 2011, Article ID: 732394. http://dx.doi.org/10.1093/ecam/neq008

Koller, D., \& Gryski, C. (2008). The Life Threatened Child and the Life Enhancing Clown: Towards a Model of Therapeutic Clowning. Evidence-Based Complementary and Alternative Medicine: eCAM, 5, 17-25. http://dx.doi.org/10.1093/ecam/nem033

Lanzieri, P. G., Claro, L. B. L., de Bragança, F. C. R., dos Santos Montezano, V. R., \& da Silva, C. S. (2011). “Good Evening, Good Morning HUAP!” An Experience of Humanization within Training for Healthcare Professionals. InterfaceComunicação, Saúde, Educação, 15, 289-298. http://dx.doi.org/10.1590/S1414-32832010005000031

Lecoq, J., Carasso, J. G., \& Lallias, J. C. (2002). The Moving Body: Teaching Creative Theatre. London: Routledge.

Leef, B. L., \& Hallas, D. (2013). The Sensitivity Training Clown Workshop: Enhancing Therapeutic Communication Skills in Nursing Students. Nursing Education Perspectives, 34, 260-264. http://dx.doi.org/10.5480/1536-5026-34.4.260

de Lima, R. A. G., Azevedo, E. F., Nascimento, L. C., \& Rocha, S. M. M. (2009). The Art of Clown Theater in Care for Hospitalized Children. Revista da Escola de Enfermagem da USP, 43, 186-193. http://dx.doi.org/10.1590/S0080-62342009000100024

Linge, L. (2010). Hospital Clowns Working in Pairs-In Synchronized Communication with Ailing Children. International Journal of Qualitative Studies on Health and Well-Being, 3, 27-38. http://dx.doi.org/10.3402/qhw.v3i1.4969

Linge, L. (2012). Magical Attachment: Children in Magical Relations with Hospital Clowns. International Journal of Qualitative Studies on Health and Well-Being, 7, 11862. http://dx.doi.org/10.3402/qhw.v7i0.11862

Masetti, M. (2003). Boas misturas: A ética da alegria no contexto hospitalar. Palas Athena.

Nogueira-Martins, M. C. F., \& Bógus, C. M. (2004). Considerações sobre a metodologia qualitativa como recurso para o estudo das ações de humanização em saúde. Saúde e Sociedade, 13, 44-57.

http://dx.doi.org/10.1590/S0104-12902004000300006

Nogueira-Martins, M. C. F., Nogueira-Martins, L. A., \& Turato, E. R. (2006). Medical Students' Perceptions of Their Learning about the Doctor-Patient Relationship: A Qualitative Study. Medical Education, 40, 322-328. http://dx.doi.org/10.1111/j.1365-2929.2006.02411.x

Oppenheim, D., Simonds, C., \& Hartmann, O. (1997). Clowning on Children’s Wards. The Lancet, 350, 1838-1840. 
http://dx.doi.org/10.1016/S0140-6736(97)07296-6

Patton, M. Q. (2002). Qualitative Research and Evaluation Methods. Thousand Oaks, CA: Sage.

Peacock, L. (2009). Serious Play: Modern Clown Performance. Intellect Ltd.

Pope, C., Ziebland, S., \& Mays, N. (2000). Qualitative Research in Health Care. Analysing Qualitative Data. British Medical Journal (Clinical Research Edition), 320, 114-116. http://dx.doi.org/10.1136/bmj.320.7227.114

Preuss, D., Schoofs, D., Schlotz, W., \& Wolf, O. T. (2010). The Stressed Student: Influence of Written Examinations and Oral Presentations on Salivary Cortisol Concentrations in University Students. Stress, 13, 221-229. http://dx.doi.org/10.3109/10253890903277579

Shooter, M. (2002). Students' Heads Are so Full of Lists They Have Forgotten How to Listen. British Medical Journal, 325, 677. http://dx.doi.org/10.1136/bmj.325.7366.677

Siegel-Itzkovich, J. (2002). Israel Sets up Course in Clowning to Help Patients Recover. British Medical Journal, $325,922$. http://dx.doi.org/10.1136/bmj.325.7370.922/b

Sorrir é Viver Medical University Clown Program Homepage (2014). http://www.sorrireviver.org/

Vagnoli, L., Caprilli, S., Robiglio, A., \& Messeri, A. (2005). Clown Doctors as a Treatment for Preoperative Anxiety in Children: A Randomized, Prospective Study. Pediatrics, 116, e563-e567. http://dx.doi.org/10.1542/peds.2005-0466

Warren, B., \& Chodzinski, R. (2005). An Interview with Dr. Bernie Warren, Clown Doctor and Founder of Fools for Health. Teaching and Learning, 2, 7-10.

Warren, B., \& Spitzer, P. (2011). Laughing to Longevity—The Work of Elder Clowns. The Lancet, 378, 562-563. http://dx.doi.org/10.1016/S0140-6736(11)61280-4

Washington University School of Medicine First Year Curriculum—Selective Courses—Medicine of Laughter (2014). http://medadmissions.wustl.edu/Education/Curriculum/Pages/FirstYear.aspx 